\title{
DEVELOPMENT AND EVALUATION OF PERSONAL URBAN CONCEPT VEHICLE POWERED BY A HYDROGEN FUEL CELL
}

\author{
Ivan BELOEV
}

"Angel Kanchev" University of Ruse, Ruse, Bulgaria

\begin{abstract}
To reduce the levels of harmful emissions and to minimize the noise pollution, many leading countries have started pilot projects and initiatives for gradual transition to electrical vehicles or vehicles powered by alternative fuel sources, including natural gas, hydrogen, propane, biofuels, and methanol. Parallel to this, many automotive companies are also exploring and using every possibility to introduce newer manufacturing technologies and materials in the vehicle development and construction processes. The results of these efforts are vehicles that are lighter and have lower fuel consumption, but at the same time are capable to provide the industry approved levels of comfort, reliability, and protection to the passengers. One of the many drivers for the abovementioned evolution of the automotive industry are the numerous events and races, where teams from different countries and continents are competing for dominance. The focus of this paper is to present the processes for design, development and evaluation of a hydrogen fuel cell powered racing vehicle, which was developed at the "Angel Kanchev" University of Ruse in Bulgaria. The paper presents results from simulated and real on-track experiments with the vehicle prototype. Emulations and analysis on the possibilities to improve the vehicle performance, as well as to increase the effectiveness of the vehicle power supply system, using a system for regenerative braking, are also provided in the last section of the paper.
\end{abstract}

Keywords: alternative fuel sources; electric vehicles; vehicle prototype; green energy

As a result of the growth of the world population and the rapid increase of its needs, the global energy demand is expected to double by 2050 (Zhenya, 2015). At the same time, the threats to the climate change are increasingly growing and deepening. This calls for the development of measures that allow the transport of passengers and goods in the cleanest possible way. The main disadvantage of the conventional road transport is its highly negative impact on the environment. This impact includes, but is not limited to, the emissions of harmful substances, the generation of noise and the consumption of large amounts of liquid fuels (Binggang et al., 2004).

In order to increase the public awareness, knowledge and understanding about the practical and scientific methods for development and use of vehicles powered by alternative fuel sources, the "Angel Kanchev" University of Ruse established in 2016 a research laboratory and a student racing team, called HydRU Racing Team. While the research laboratory is focused on the scientific study and evaluation of alternative fuel sources and their use in different industries, the main goal of the student racing team is to participate in international and national forums and competitions, which promote the relevance and importance of the vehicles powered by alternative energy sources.

Over the years, HydRU Racing Team has produced three vehicle prototypes, which have participated in different editions of Shell Eco Marathon (SEM) - one of the most renowned international competitions for educational institutions, where the teams are trying to achieve the furthest driving distance possible with a specific amount of fuel. All the vehicles were designed as single person concept vehicles, which are to be used as delivery vehicles or for transportation in dense urban environments.

\section{Material and methods}

The first phase of the vehicle development workflow for the HydRU Racing Team prototype was to analyse similar vehicles and to build up on the experience of the leading teams, which have developed prototypes of urban concept vehicles and have participated in international racing events (Hashimoto et al., 2004; Carello et al., 2014; Omar et al., 2015). The main goal of the team, led by the author of this publication, was to use widely available materials and technologies and in accordance with the team budget to create a prototype of an urban concept vehicle that will participate in SEM - Europe 2019. To achieve this goal, the team was divided into working groups, which consisted of representatives from different faculties of the university so that the work process can be optimized. The end result of the work were several conceptual sketches of the body and of the chassis of the vehicle, as well as the definition and evaluation of the dynamic characteristics of the materials that were to be used to make the car. As a final result, it was decided that the vehicle chassis will be hybrid and the suspension elements will be mounted directly on the coupe, which will decrease the overall vehicle body (Fig. 1A). A novelty for the team was the use of vacuum lamination technologies. The body and the chassis of the

Contact address: Ivan Beloev, “Angel Kanchev”University of Ruse, Department of Transport, Ruse, Bulgaria, e-mail: ibeloev@uni-ruse.bg 

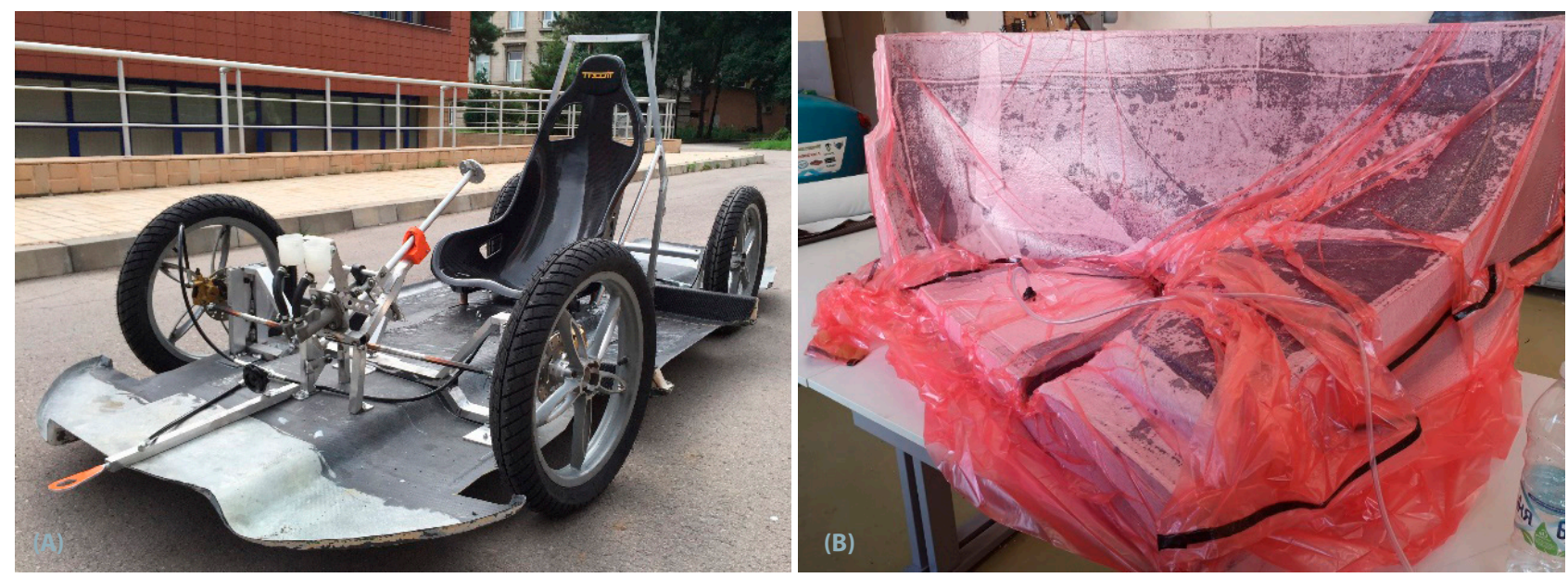

Fig. 1 The developed chassis of the vehicle (A) and implementation of vacuum lamination technologies for the preparation of the vehicle body parts $(B)$

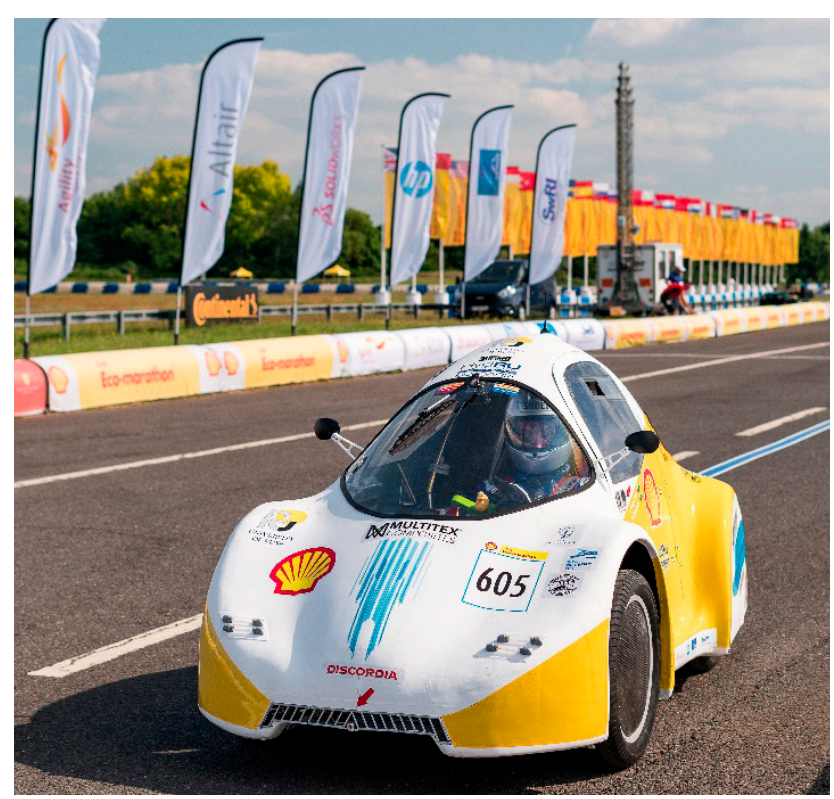

Fig. 2 The developed vehicle prototype during the Shell Eco Marathon 2019 competition vehicle was created using carbon fabric and lamination resins (Fig. 1B).

Thanks to these innovative technologies, a 15\% reduction in the weight of the vehicle was achieved, compared to the weight of the vehicle created in 2018. For the production of the vehicle parts, a carbon fabric with density of $600 \mathrm{~g} \cdot \mathrm{m}^{-2}$ was used, as well as a lamination epoxy resin SIKA CR82, which is characterized by extremely good resistance to external influences and good tolerance to temperature variations. The developed vehicle is shown in Fig. 2.

The calculation of the top speed of the prototype is the basic requirement for the sizing of the vehicle gears and the propulsion system. The information used in the calculations was provided by the organizers of the event and is presented in Fig. 3.

Using the information from Fig. 3, it can be easily calculated that to meet the requirements of the track, the average speed must be $25 \mathrm{~km} \cdot \mathrm{h}^{-1}$. As defined in the race rules, all urban concept vehicles must stop on every request of the track marshals, as well as on a virtual traffic light for at least once per lap. The calculated speed of $25 \mathrm{~km} \cdot \mathrm{h}^{-1}$ is in the ideal conditions when the car does not have to stop every lap. If the time that will be spent for each stop has to be taken into account, then the vehicle halt time must

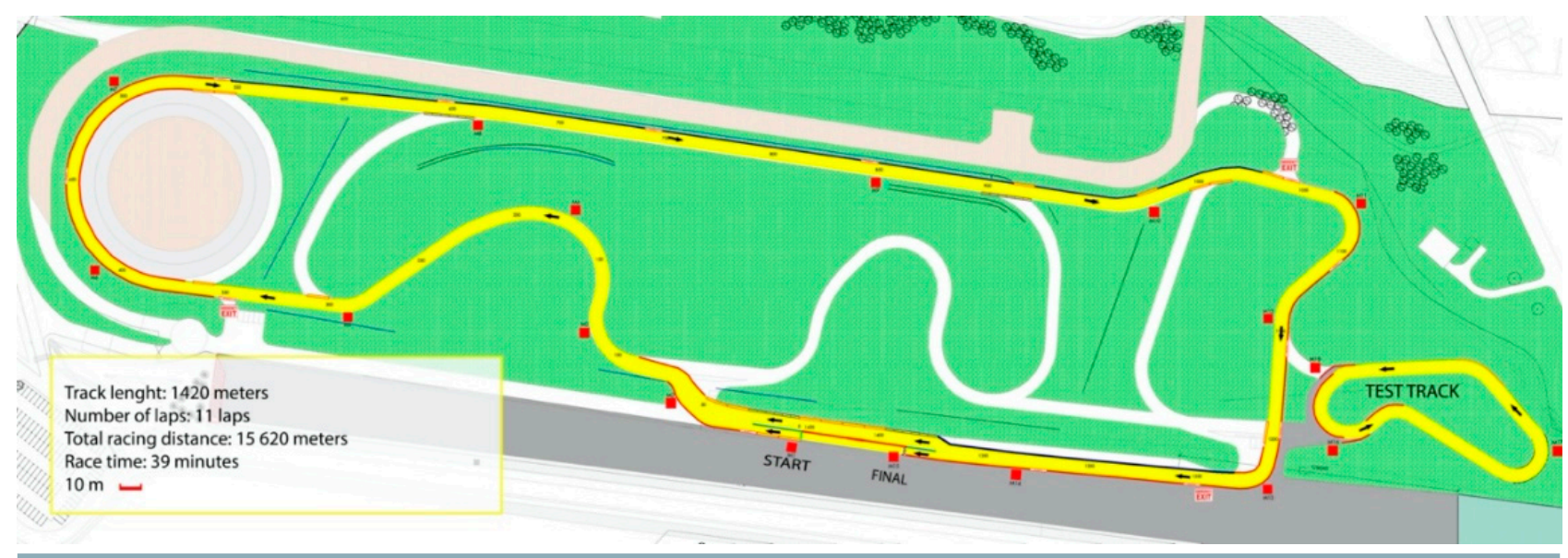

Fig. 3 Information about the racetrack provided by the organizers 
be considered when calculating the average speed. It can be assumed that these processes are taking around 30 seconds to complete. Therefore, in order to meet the conditions to finish the race in 39 minutes, every lap must be completed in less than 210 seconds, which will require an increase of the average speed to $29-30 \mathrm{~km} \cdot \mathrm{h}^{-1}$.

The final result of the development process was the creation of an urban concept vehicle, which is powered by a hydrogen fuel cell and uses the most efficient and the best price-to-value components. The selection of every part is relevant to the final energy efficiency of the vehicle. When determining the dynamic characteristics of the vehicle prototype, several main forces, which are affecting the movement, must be taken into account, including the acceleration force and the three opposite drag momentums, which are created as a result of the air resistance, the rolling resistance and the ascent slope (Moinar and Shahgoli, 2019). The losses caused by the air and the rolling resistance are not recoverable at all, while the losses caused by the ascent and the acceleration are partially recoverable. The force that opposes the movement of the vehicle consists of two components - resistance caused by the shape of the vehicle and friction between the air molecules and the surface of the vehicle (Di Martino, 2005). This force can be expressed by the following equation:

$$
F_{a}=\frac{1}{2} \delta C_{d} A v^{2}
$$

where:

$\delta$ - the air density $\left(\mathrm{kg} \cdot \mathrm{m}^{-3}\right) ; C_{d}$ - the aerodynamic coefficient dependant on the shape of the vehicle; $A$ - the area of the widest section of the vehicle $\left(\mathrm{m}^{2}\right)$; $v$ - the movement speed $\left(\mathrm{m} \cdot \mathrm{s}^{-1}\right)$, (Di Martino, 2005)

The aerodynamic coefficient varies between 0.15 and 0.50 for cars with poor aerodynamic characteristics. When the car is moving, two zones are created - one in the front of the vehicle, where the air pressure is higher, and one in the rear part of the vehicle, where the air pressure is low. These two zones are the reason for the resulting effect, which is expressed as the resistance to the linear motion of the vehicle. To determine the aerodynamic coefficient in the case of the developed vehicle prototype, a computer modelling process was performed using the computational fluid dynamics methods (Fig. 4A and Fig. 4B). Using the general equations for aerodynamic drag and rolling resistance (Guzzella and Sciarretta, 2007), the power required to maintain an average speed of $29 \mathrm{~km} \cdot \mathrm{h}^{-1}$ can be calculated. The results shown in Fig. 4C are obtained with a driver weight of $70 \mathrm{~kg}$, total vehicle weight of $120 \mathrm{~kg}$ and air density at temperature of $25^{\circ} \mathrm{C}$. However, it is strongly desirable for the vehicle to have a slightly higher speed limit, so that in the case of an unplanned emergency stop, the lost time can be compensated. For this reason, it is considered that the top speed of the vehicle should be $35 \mathrm{~km} \cdot \mathrm{h}^{-1}$. According to Fig. 5, this will lead to increase in the required power from $260 \mathrm{~W}$, which is needed for top speed of $29 \mathrm{~km} \cdot \mathrm{h}^{-1}$, to $350 \mathrm{~W}$, which will guarantee the top speed of $35 \mathrm{~km} \cdot \mathrm{h}^{-1}$.

For the selection of a DC electric motor for the vehicle, a thorough review of the commercially available options was made (Harnefors, 2002; Mohan et al., 2003). The main racing strategy was to choose the proper electric motor - one that can produce
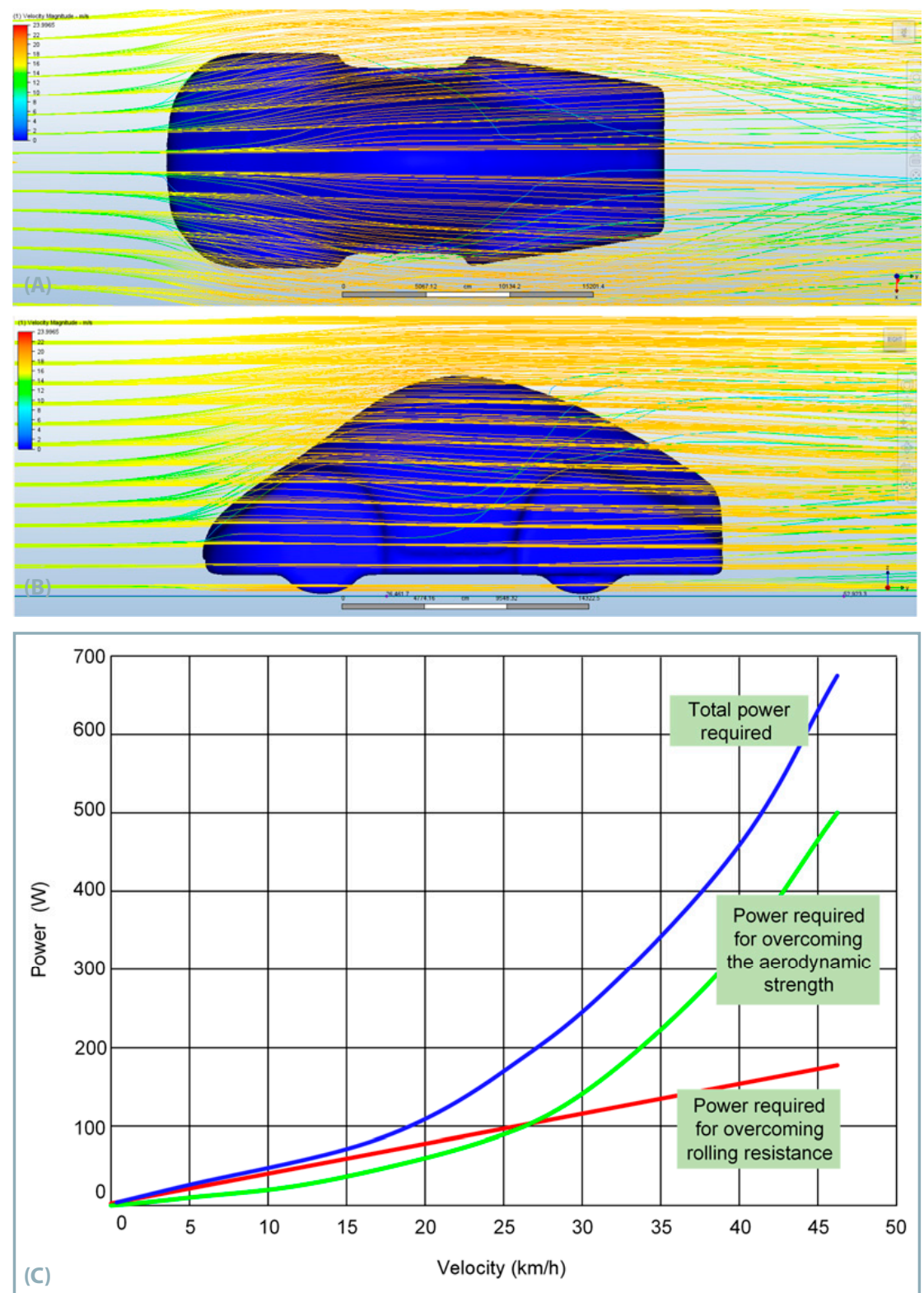

Fig. 4 Aerodynamic analysis of the vehicle (A, B) and summarized vehicle power requirements $(C)$ 
Table 1 Gear ratio to speed dependences at different voltage levels

\begin{tabular}{|l||c|c|c|}
\hline No & Gear ratio & Speed at 36 V & Speed at 48 V \\
\hline \hline $\mathbf{1}$ & $10: 1$ & $39 \mathrm{~km} \cdot \mathrm{h}^{-1}$ & $54 \mathrm{~km} \cdot \mathrm{h}^{-1}$ \\
\hline $\mathbf{2}$ & $11: 1$ & $36 \mathrm{~km} \cdot \mathrm{h}^{-1}$ & $49 \mathrm{~km} \cdot \mathrm{h}^{-1}$ \\
\hline $\mathbf{3}$ & $12: 1$ & $33 \mathrm{~km} \cdot \mathrm{h}^{-1}$ & $45 \mathrm{~km} \cdot \mathrm{h}^{-1}$ \\
\hline $\mathbf{4}$ & $13: 1$ & $30 \mathrm{~km} \cdot \mathrm{h}^{-1}$ & $42 \mathrm{~km} \cdot \mathrm{h}^{-1}$ \\
\hline $\mathbf{5}$ & $14: 1$ & $28 \mathrm{~km} \cdot \mathrm{h}^{-1}$ & $39 \mathrm{~km} \cdot \mathrm{h}^{-1}$ \\
\hline $\mathbf{6}$ & $15: 1$ & $26 \mathrm{~km} \cdot \mathrm{h}^{-1}$ & $36 \mathrm{~km} \cdot \mathrm{h}^{-1}$ \\
\hline
\end{tabular}

the required power, but will operate in the most nominal mode possible (Hughes, 2006). Unfortunately, the market availability of highly efficient DC motors, which are corresponding to the vehicle power requirements, is quite scarce. Nevertheless, it was decided to use two Maxon RE50 DC motors with nominal power of $200 \mathrm{~W}$ each and with efficiency of $86 \%$, which corresponds to the presented requirements. To meet the requirements for reaching $350 \mathrm{~W}$ of propulsion power, both electric motors are mounted in a parallel gear system with a fixed gear ratio. The dynamic characteristics of the motors, which were published by the manufacturer (RE50 datasheet, 2020), show that the RE50 is designed to work at lower currents, but at higher voltage levels. The motor is also characterised by a tiny efficiency drop at voltage levels of $40 \mathrm{~V}$. This gives the motor a wide efficiency tolerance, which is from around 3000 rpm to its maximal rotational speed of $7700 \mathrm{rpm}$. The torque achieved in this zone is between $150 \mathrm{mNm}$ and

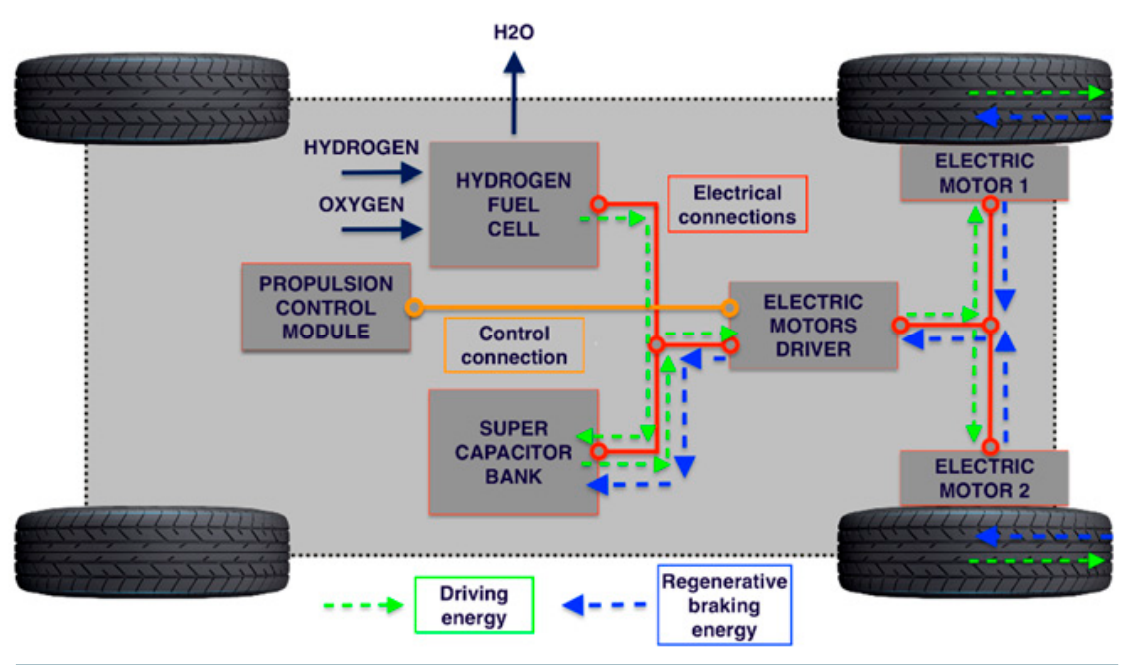

Fig. 5 Propulsion diagram of the constructed urban concept vehicle prototype the chemical reaction are obtained (Chan, 2007). Thus, the fuel cell can produce energy continuously and as long as the supply of reactants is taking place. The hydrogen cell that is used for the construction of the urban concept vehicle is providing $1000 \mathrm{~W}$ of power, with a maximal output voltage without load of up to $50 \mathrm{~V}$ and nominal voltage under load of $36 \mathrm{~V}$. Unfortunately, fuel cells cannot store the produced energy (Dixon, 2010) like the batteries, but when combined with super capacitors, they produce a highly reliable energy storage system (Westbrook, 2001). The efficiency of such systems that convert electricity into hydrogen and vice versa is about $40 \%$, but theoretically it can reach up to $60 \%$ (Zhao et al., 2020).

\section{Results and discussion}

Fig. 5 shows the drive diagram of the constructed urban concept vehicle. The main element is the hydrogen fuel cell that converts the chemical energy from the oxidation of hydrogen into electrical energy. The structure of the conventional fuel cell is similar to that of the galvanic cell (battery), with the main difference being the fact that fuel cells are designed for continuous supply of input resources (Ehsani et al., 2005; Robert Bosch GmbH, 2000). The reactants used in the fuel cell are hydrogen (fuel element), which is supplied to the anode side, and oxygen (supplied from the air), which is provided on the cathode side (hydrogen cell). A typical property for a fuel cell is the fact that once the supply of reactants is made, the products from

The results presented in this chapter are obtained from real experiments that comply with the requirements of the competition. Among these requirements are the time to complete the required number of laps and the related lowest speed. The speed threshold set by the organizers of the Shell Eco Marathon competition is $25 \mathrm{~km} \cdot \mathrm{h}^{-1}$, but as there are several necessary stops that must be made during the race, the lowest possible speed that will guarantee the completion of the competition is 29 $\mathrm{km} \cdot \mathrm{h}^{-1}$, as discussed in the previous section.

During the race, all vehicle parameters are registered by a telemetry system, which is able to record the data about the movement of the vehicle (coordinates, speed, acceleration, etc.), as well as to produce detailed statistics about the energy consumption. Figures 6, 7 and 8 present the trajectory, the speed, the consumption of the vehicle electronics and the hydrogen consumption, which is recorded by the telemetry system mounted on the vehicle.

By analysing the results from the figures, two main conclusions can be deducted - the vehicle has good dynamic characteristics and overcomes the track elevation gains with a minimal energy consumption. The highest energy consumption, as seen in the figures, is during the acceleration of the vehicle, so that it 

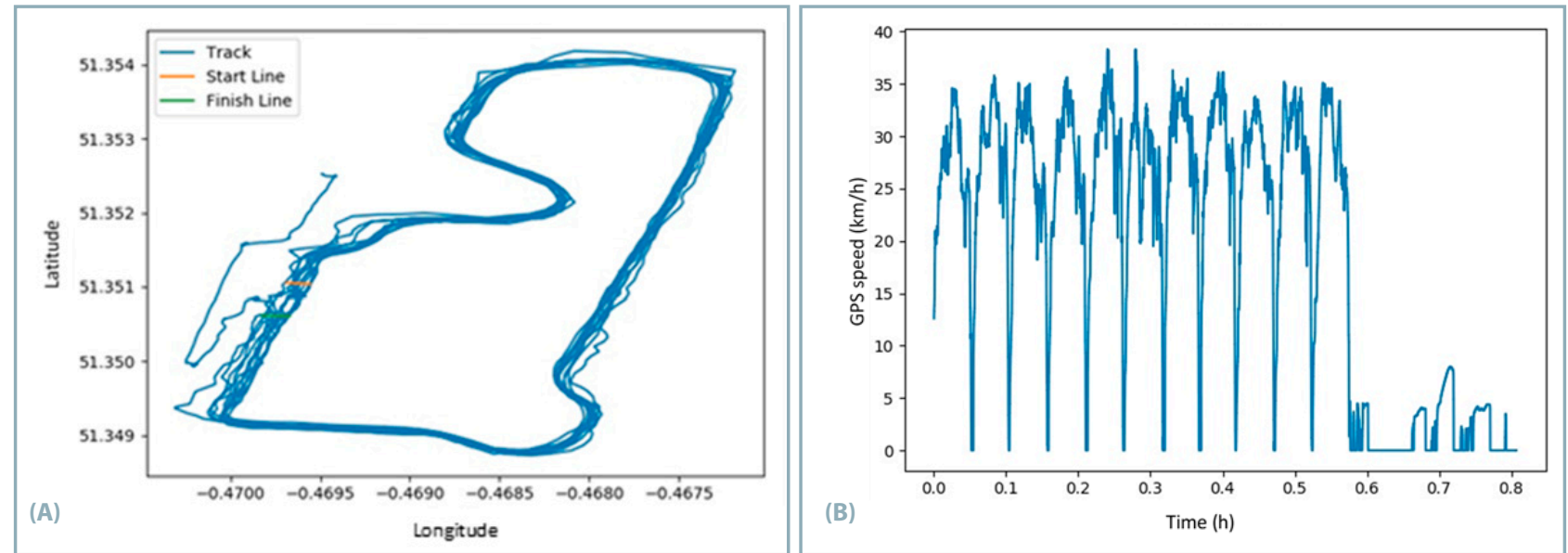

Fig. 6 Vehicle movement trajectory based on GPS coordinates (A) and speed in $\mathrm{km} \cdot \mathrm{h}^{-1}(\mathrm{~B})$
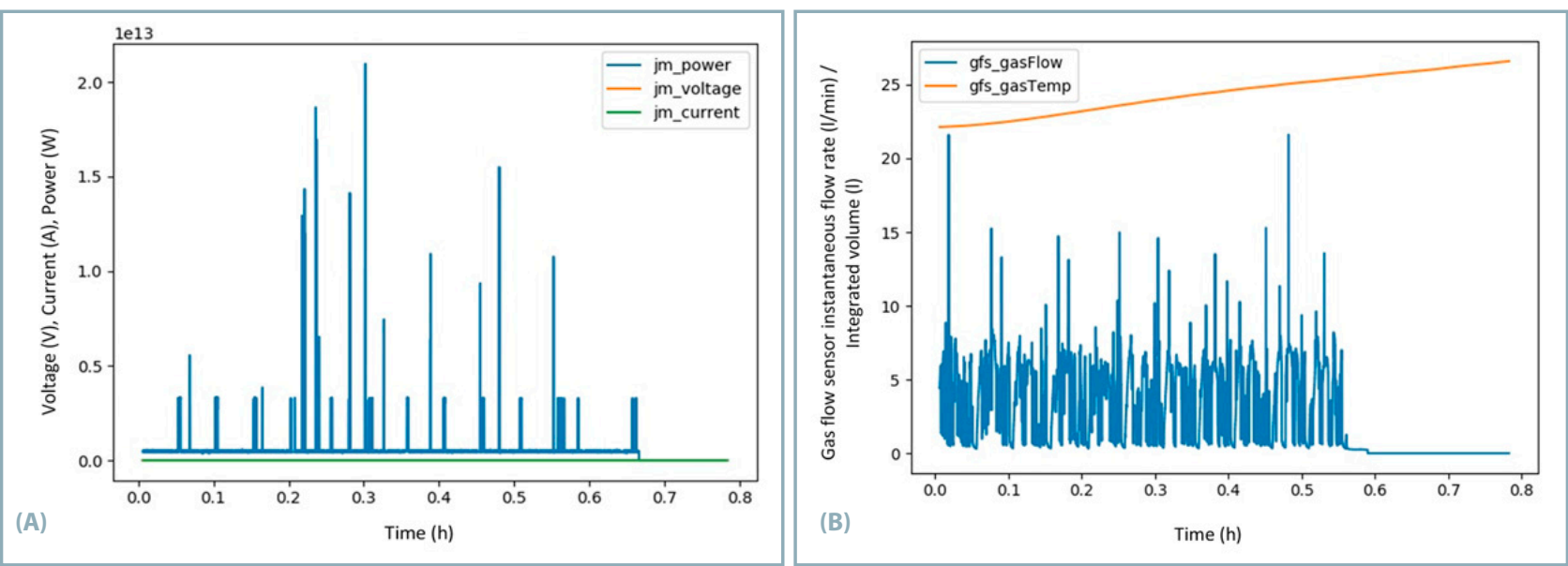

Fig. 7 Consumption of the on-board electronics (A) and hydrogen consumption in $1 \cdot \mathrm{min}^{-1}(B)$
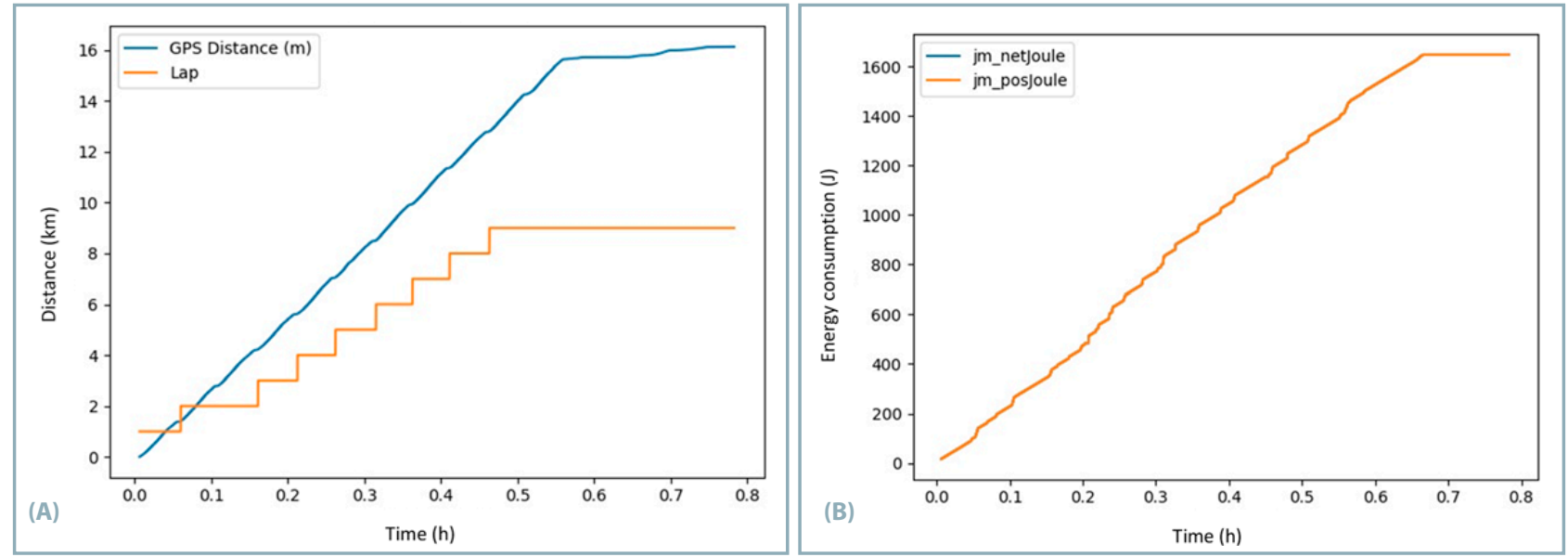

Fig. 8 Distance by GPS and number of laps (A) and energy consumption per lap in J (B)

can reach a nominal speed of $27-30 \mathrm{~km} \cdot \mathrm{h}^{-1}$. In the evaluation tests, which emulate the movement of the vehicle in urban environments, the average consumption of hydrogen is $0.85 \mathrm{~m}^{3}$ per $100 \mathrm{~km}$. In the evaluation experiments, the concepts of the electromechanical circuits for regenerative (generator) braking were not used. These systems can generate energy from the vehicle braking and thus can compensate part of the energy that is needed for the initial vehicle acceleration after each stop (Yoong et al., 2011).

Based on the performed experiments and the collected results, a MATLAB/Simulink model (Mercier, 2020) was modified and parameterised to assess the impact of 
the regenerative braking and the possibility to accumulate energy on the overall energy efficiency of the vehicle prototype. The model consists of four modules. The first module represents the electrical subsystem that simulates the functions of the motors, the battery, the fuel cell and the DC/DC converter. The second module is responsible for the vehicle dynamics and emulates the functions of all mechanical parts of the vehicle. The energy management subsystem is simulated in the third module. It defines the reference signals that control the electric motors. The fuel cell control system, which is also responsible for the management of the DC/DC converter, represents the fourth system. Its primary function is to accurately distribute the energy
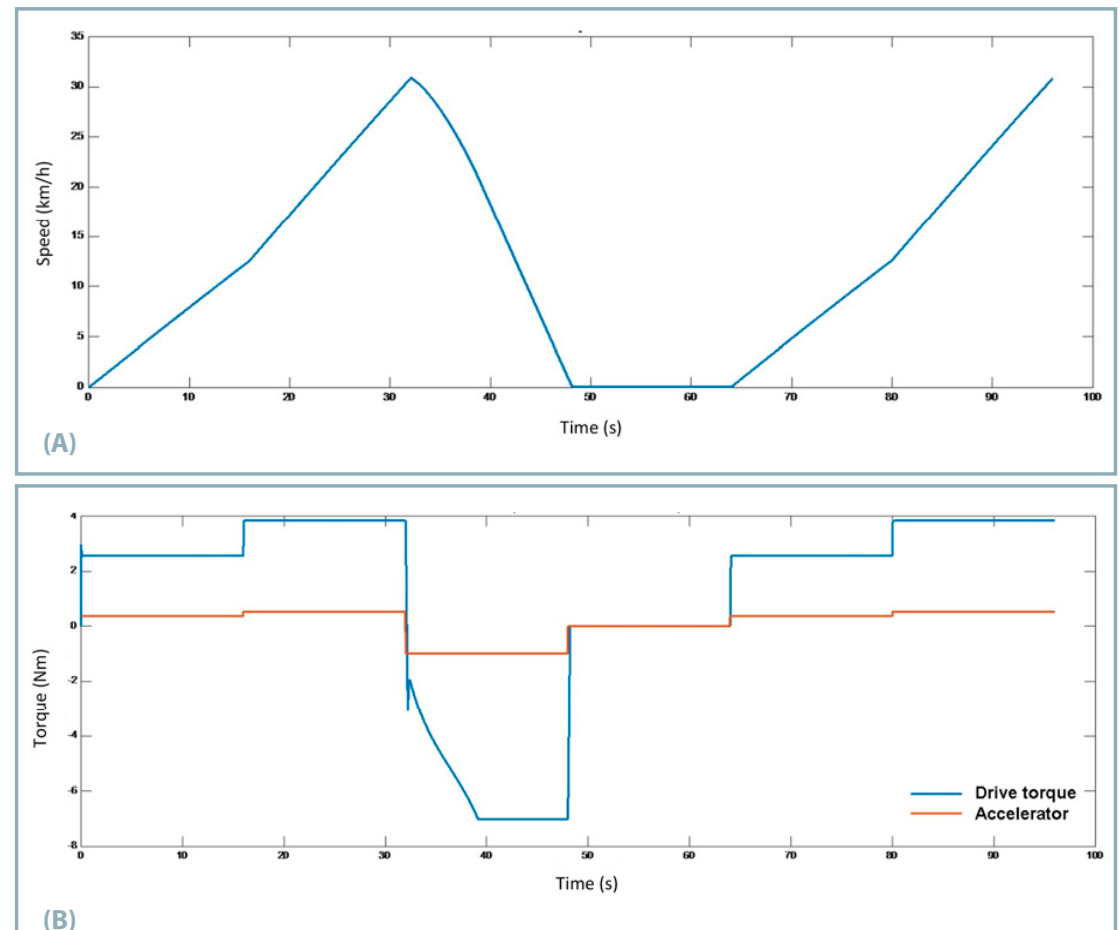

(B)

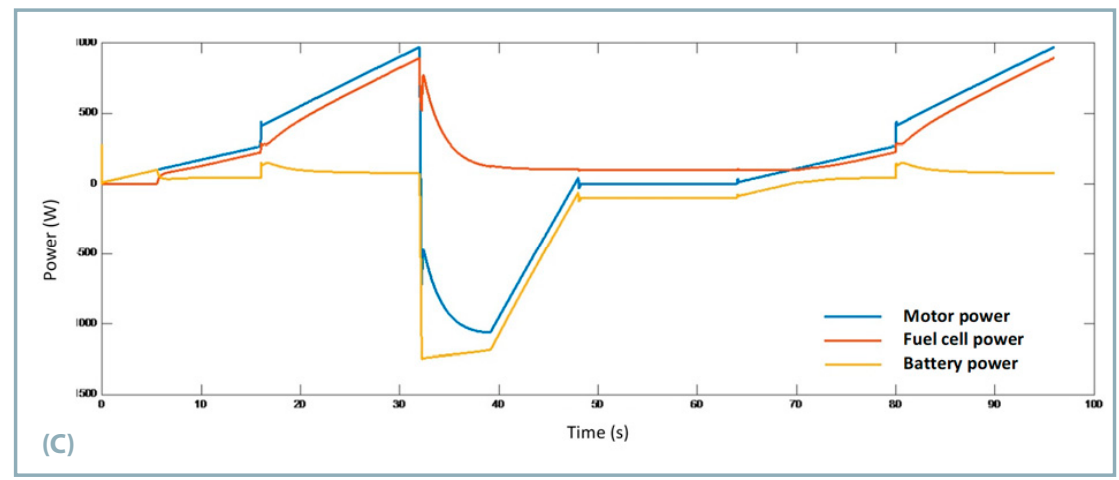

Fig. 9 Simulation results and graphs for the speed (A), torque (B) and power (C), which are used to assess the impact of the regenerative braking and the possibility of energy storage

from the two available power sources. The control signals are a function of the measured speed and the position of the drive control module, which is represented by a signal between -1 and 1.

The results of the simulation, which covers a scenario with three events acceleration to a speed of $30 \mathrm{~km} \cdot \mathrm{h}^{-1}$, breaking to the complete rest of the vehicle followed by a 10 -seconds long rest and then again acceleration to the speed of $30 \mathrm{~km} \cdot \mathrm{h}^{-1}$, are shown in Fig. 9.

As the regenerative braking function is activated in this scenario, during the braking processes, the torque of the rear axle shows a negative value, which indicates the recovery of kinetic energy. Meanwhile, the power of the supercapacitors is is corresponding to the specific requirements of the Shell Ecomarathon competition, but it is also presenting the opportunity to be used in different other application domains - for transportation of goods in urban areas, for postal services and above all for different agriculture purposes. While there are numerous eco-friendly technologies and energy regeneration or recovery mechanisms, many of them are still not used in the agricultural domain, where the majority of the field vehicles are diesel powered. Additionally, the field operations are usually done on specific areas and following specific patterns, which require the constant stopping and turning of the agricultural machines, which as presented above can be used for the recovery of some of the energy.

\section{Conclusion}

The article evaluates the energy efficiency of a vehicle prototype powered by a hydrogen fuel cell. Based on real experiments and evaluation data, a simulation model is used to assess the impact of a regenerative braking system and the possibility to accumulate energy. The obtained results can be used for the improvement of the vehicle in two main directions. The first one is the introduction of a gearbox, which will provide the ability to change the gears (gear ratio) when torque is generated by the motors. The second improvement will be the 
introduction of an electromechanical circuit for regenerative braking. It will allow the generation and the storage of the energy from braking and will partially compensate for the energy loss during the initial acceleration of the vehicle after each stop. The electronic modules for implementation of the system for regenerative braking are under development. They will synchronize the regenerative braking system with the hydraulic braking system of the vehicle and will provide the driver with good level of comfort, while at the same time will ensure that the maximum amount of kinetic energy is collected and stored. These planned improvements are expected to lead to increase in the vehicle performance and to boost the overall energy efficiency of the prototype. This could lead to better on-track results and will provide opportunity for higher ranking in the next Shell Eco Marathon competitions. Additionally, the vehicle can be further improved with the addition of different energy harvesting solutions, like a photovoltaic system with solar panels (Kafui et al., 2019).

\section{Acknowledgments}

This work is completed as a partial fulfilment of Project 2020-RU-02 "Study of the Possibilities for Optimization of an Urban Concept Vehicle Prototype Powered by a Hydrogen Fuel Cell", financed under the Scientific and Research Fund of the "Angel Kanchev" University of Ruse.

\section{References}

CAMILLERI, R. - ARMSTRONG, P. - EWIN, N. - RICHARDSON, R. HOWEY, D. A. - MCCULLOCH, M. D. 2013. The value of a clutch mechanism in electric vehicles. In World Electric Vehicle Journal, vol. 6, no. 3, pp. 696-706.

BINGGANG, C. - CHUANWEI, Z. - ZHIFENG, B. - JINGCHENG, L. 2004. Technology progress and trends of electric vehicles. In Journal of Xi'an Jiaotong University, vol. 38, no. 1, pp. 1-5.

CARELLO, M. - BONANSEA, P. - D'AURIA, M. 2014. Driveline optimization for a hybrid electric city vehicle to minimize fuel consumption. SAE Technical Paper no. 2014-01-1090.

CHAN, C. C. 2007. The state of the art of electric hybrid and fuel cell vehicles. In Proceedings of the IEEE, vol. 95, no. 4, pp. 704-718.

DI MARTINO, R. 2005. Modelling and Simulation of the Dynamic Behaviour of the Automobile. Auto-matic. Université de Haute Alsace - Mulhouse. Doctoral Thesis.

DIXON, J. 2010. Energy storage for electric vehicles. In 2010 IEEE International Conference on Industrial Technology (ICIT). Piscataway, New Jersey : IEEE, pp. 20-26. ISBN 9781424456956.

GUZZELLA, L. - SCIARRETTA, A. 2007. Vehicle Propulsion Systems: Introduction to Modelling and Optimization. $2^{\text {nd }}$ ed. Berlin, Heidelberg : Springer-Verlag, 338 pp. ISBN 9783540746911.

HARNEFORS, L. 2002. Control of Variable-Speed Drives, Applied Signal Processing and Control. Department of Electronics, Mälardalen University, 195 pp.

HASHIMOTO, N. - OMAE, M. - SHIMIZU, H. 2004. Development of multi-purpose small electric vehicle with application of automated guiding control system. In Journal of Asian Electric Vehicles, vol. 2, no. 1, pp. 557-563.
HE, X. - MAXWELL, T. - PARTEN, M. 2006. Development of a hybrid electric vehicle with a hydrogen-fueled IC engine. In IEEE Transactions on Vehicular Technology, vol. 55, no. 6. pp. 1693-1703. HUGHES, A. 2006. Electric Motors and Drives: Fundamentals, Types and Applications. $3^{\text {rd }}$ ed. Oxford and Boston : Newnes, 384 pp. ISBN 9780750647182

EHSANI, M. - GAO, Y. - GAY, S. E. - EMADI, A. 2005. Modern Electric, Hybrid Electric, and Fuel Cell Vehicles - Fundamentals, Theory, and Design. Boca Raton: CRC Press LLC, 419 pp. ISBN 0849331544.

KAFUI, A. - SERES, I. - FARKAS, I. 2019. Efficiency comparison of different photovoltaic modules. In Acta Technologica Agriculturae, vol. 22, no. 1, pp. 5-11.

MOHAN, N. - UNDELAND, T. M. - ROBBINS, W. P. 2003. Power Electronics, Converters, Applications and Design. $3^{\text {rd }}$ ed. Hoboken, New Jersey : John Wiley \& Sons, Inc., 832 pp. ISBN 9780471226932.

MERCIER, P. 2021. Fuel Cell Vehicle (FCV) Power Train. MATLAB Central File Exchange. Available at:

https://www.mathworks.com/matlabcentral/

fileexchange/33309-fuel-cell-vehicle-fcv-power-train

MOINAR, A. - SHAHGHOLI, G. 2019. The effect of tractor driving system type on its slip and rolling resistance and its modelling using ANFIS. In Acta Technologica Agriculturae, vol. 22, no. 4, pp. 115-121.

RE50 DATASHEET. 2020. Maxon motor RE50 technical datasheet. Maxon Motor AG. Available at: https://www.maxongroup.com/ medias/sys master/root/8841119367198/EN-133.pdf

ROBERT BOSCH GmbH. 2000. Automotive Handbook. $5^{\text {th }}$ ed. Stuttgart, Germany : Society of Automotive Engineers (SAE), 962 pp. ISBN 0768006694.

THANAPALAN, K. - ZHANG, F. - PREMIER, G. - MADDY, J. - GUWY, A. 2012. Energy management effects of integrating regenerative braking into a Renewable Hydrogen Vehicle. In Proceedings of 2012 UKACC International Conference on Control, pp. 924-928.

OMAR, S. M. H. S. - ARSHAD, N. M. - YASSIN, I. M. - FAKHARUZI, M. H. A. M. - WARD, T. 2015. Design and optimization of powertrain system for prototype fuel cell electric vehicle. In Journal of Mechanical Engineering and Sciences, vol. 8, pp. 1401-1413.

WESTBROOK, M. H. 2001. The Electric Car: Development and Future of Battery, Hybrid and Fuel-Cell Cars. London, Savoy Place : Institution of Engineering and Technology, 216 pp. ISBN 9780852960134.

YOONG, M. K. - GAN, Y. H. - GAN, G. D. - LEONG, C. K. - PHUAN, Z. Y. - CHEAH, B. K. - CHEW, K. W. 2011. Studies of regenerative braking in electric vehicle. In IEEE Conference on Sustainable Utilization and Development in Engineering and Technology. Piscataway, New Jersey : IEEE, pp. 40-45. ISBN 9781424475049.

ZHENYA, L. 2015. Supply and Demand of Global Energy and Electricity. In Global Energy Interconnection. Cambridge, Massachusetts: Academic Press, pp. 101-182. ISBN 9780128044056. ZHAO, Y. - SONG, H. - LIU, Y. - YU, Z. 2020. Energy management of dual energy source of hydrogen fuel cell hybrid electric vehicles. SAE Technical Paper no. 2020-01-0595. 